OPEN ACCESS

Edited by:

John Doonan,

Aberystwyth University, UK

Reviewed by:

Antonio Ferrante,

University of Milan, Italy

Liezhao Liu,

Southwest University, China

*Correspondence:

Jianxia Zhang

zhangjx666@126.com

${ }^{t}$ These authors have contributed

equally to this work.

Specialty section:

This article was submitted to Crop Science and Horticulture,

a section of the journal

Frontiers in Plant Science

Received: 08 July 2016 Accepted: 17 February 2017

Published: 07 March 2017

Citation:

Yu D, Zhang L, Zhao K, Niu R,

Zhai $H$ and Zhang $J(2017)$

VaERD15, a Transcription Factor Gene Associated with Cold-Tolerance in Chinese Wild Vitis amurensis.

Front. Plant Sci. 8:297.

doi: $10.3389 /$ fpls.2017.00297

\section{VaERD15, a Transcription Factor Gene Associated with Cold-Tolerance in Chinese Wild Vitis amurensis}

\author{
Dongdong Yu $u^{1,2,3+}$, Lihua Zhang ${ }^{1,2,3 \dagger}$, Kai Zhao ${ }^{1,2,3}$, Ruxuan Niu'1,2,3, Huan Zhai ${ }^{1,2,3}$ and \\ Jianxia Zhang ${ }^{1,2,3 *}$
}

${ }^{1}$ College of Horticulture, Northwest A\&F University, Yangling, China, ${ }^{2}$ Key Laboratory of Horticultural Plant Biology and Germplasm Innovation in Northwest China, Ministry of Agriculture, Yangling, China, ${ }^{3}$ State Key Laboratory of Crop Stress Biology in Arid Areas, Northwest A\&F University, Yangling, China

Early responsive to dehydration $(E R D)$ genes can be rapidly induced to counteract abiotic stresses, such as drought, low temperatures or high salinities. Here, we report on an ERD gene (VaERD15) related to cold tolerance from Chinese wild Vitis amurensis accession 'Heilongjiang seedling'. The full-length VaERD15 cDNA is $685 \mathrm{bp}$, including a 66 bp 5'-untranslated region (UTR), a 196 bp 3'-UTR region and a 423 bp open reading frame encoding 140 amino acids. The VaERD15 protein shares a high amino acid sequence similarity with ERD15 of Arabidopsis thaliana. In our study, VaERD15 was shown to have a nucleic localization function and a transcriptional activation function. Semi-quantitative PCR and Western blot analyses showed that VaERD15 was constitutively expressed in young leaves, stems and roots of $V$. amurensis accession 'Heilongjiang seedling' plants, and expression levels increased after low-temperature treatment. We also generated a transgenic Arabidopsis Col-0 line that over-expressed VaERD15 and carried out a cold-treatment assay. Real-time quantitative PCR (qRTPCR) and Western blot analyses showed that as the duration of cold treatment increased, the expression of both gene and protein levels increased continuously in the transgenic plants, while almost no expression was detected in the wild type Arabidopsis. Moreover, the plants that over-expressed VaERD15 showed higher cold tolerance and accumulation of proline, soluble sugars, proteins, malondialdehyde and three antioxidases (superoxide dismutase, peroxidase, and catalase). Lower levels of relative ion leakage also occurred under cold stress. Taken together, our results indicate that the transcription factor VaERD15 was induced by cold stress and was able to enhance cold tolerance.

Keywords: grapevine, Vitis amurensis, VaERD15, cold tolerance, functional analysis

Abbreviations: AtGAPDH, Arabidopsis thaliana glyceraldehyde 3-phosphate dehydrogenase; CAT, catalase; CBF, C-repeatbinding factor; cDNA, complementary DNA; $D R E B 1$, dehydration responsive element-binding factor 1; $E R D$, early responsive to dehydration; EST, expressed sequence tag; GFP, green fluorescent protein; GUS, $\beta$-glucuronidase; MDA, malondialdehyde; MS, Murashige and Skoog; NCBI, National Center for Biotechnology Information; ORF, open reading frame; PCR, polymerase chain reaction; POD, peroxidase; qRT-PCR, real-time quantitative polymerase chain reaction; ROS, reactive oxygen species; SOD, superoxide dismutase; WT, wild type. 


\section{INTRODUCTION}

Grapevine (Vitis vinifera L.) is one of the most important multiuse fruiting plants of the world, and its berries are used in wine-making, or eaten fresh or dried. In addition to their value as a food (providing sugars, roughage etc.), grapes and their processed products have also been shown to have nutraceutical benefits including those attributed to resveratrol, which has a role in preventing and treating cardiovascular disease and cancer (Jeandet et al., 1995; Yang et al., 2009). These beneficial properties have fostered the recent growth in the grape industry.

The majority of commercial grape cultivars belong to the European grape ( $V$. vinifera L.). While these cultivars have excellent organoleptic qualities, they suffer relatively poor tolerance to the cold experienced during winter, resulting in significant damage to grapevines growing in the cooler regions of the world, including northern America and northern China.

China has abundant resources of wild grape germplasm. These include $V$. amurensis, a species that can tolerate very low winter temperatures approaching $-32^{\circ} \mathrm{C}$. Therefore, this species has great potential as a germplasm resource for cold-resistant breeding (He and Niu, 1989). Study of the cold-tolerance genes in $V$. amurensis has significantly contributed to understanding the mechanisms of cold-tolerance, as well as transgenic breeding (Xu et al., 2014a,b).

In Arabidopsis, ERD genes can be induced within $1 \mathrm{~h}$ by drought stress (Kiyosue et al., 1994). Kiyosue et al. (1994) divided a total of $26 E R D$ cDNA clones into 16 different gene families based on their expression in response to drought. Early research on ERDs was concentrated on Arabidopsis, and many studies have shown that ERD genes can be induced by a diversity of stresses including drought (Rai et al., 2012), low temperature (Kiyosue et al., 1998), salinity (Rai et al., 2015) and abscisic acid (ABA) (Aalto et al., 2012). In recent years, ERD genes have been isolated from corn (Liu et al., 2009), soybeans (Alves et al., 2011a), tobacco (Shao et al., 2014), and tomato (Ziaf et al., 2016). Importantly, their roles in response to a range of stresses have been identified. However, of these ERDs, only ERD6, ERD10, and ERD15 are related to cold tolerance in Arabidopsis. The first of these, ERD6, encodes a sugar carrier protein and is induced by low temperatures and moisture stress (Kiyosue et al., 1998). The gene AtERD10 is induced by cold and regulates $C B F$ transcription factors, and the transfer DNA (T-DNA) insertion silence strain of AtERD10 reduces stress tolerance of mutants compared with wild type Arabidopsis plants (Kim and Nam, 2010). An earlier report indicates that, at low temperatures, $S p E R D 15$ can protect the cell membrane, improve photosynthetic efficiency and promote the accumulation of soluble substances (Ziaf et al., 2011). However, another report (Kariola et al., 2006) showed that over-expression of AtERD15 decreased the sensitivity to ABA, tolerance to drought, and also to low temperatures. Conversely, the AtERD15 mutant was more sensitive to ABA and enhanced the tolerance to salinity and drought (Kariola et al., 2006). Therefore, in different plants, ERD15 may have different functions. There have been no previous reports on the ERD genes in Chinese wild Vitis spp., and for this reason we are keen to explore the role of ERD15 in V. amurensis.
We have already confirmed that $V$. amurensis is the most cold-resistant species of the 18 wild grapes species native to China and the seven wild grapes species native to North America (Zhang et al., 2012). Subsequently, a cold-induced cDNA library was constructed using potted plants of $V$. amurensis accession 'Heilongjiang seedling', in which one EST sequence encoding the ERD protein was obtained, and the gene was named as VaERD15. Real-time quantitative PCR (qRT-PCR) analyses revealed that VaERD15 was induced by cold stress (Zhang et al., 2013). In this study, we clone the full-length VaERD15, and confirm its function in response to cold stress.

\section{MATERIALS AND METHODS}

\section{Plant Materials and Growth Conditions}

Plants of Chinese wild $V$. amurensis accession 'Heilongjiang Seedling', which originates in northeast China, were maintained in the grape germplasm repository at the Northwest A \& F University, Yangling, Shaanxi, the People's Republic of China. This accession is highly resistant to cold (Zhang et al., 2012).

In early January 2010, 1-year-old shoots were taken from mature vines for sand-storage at under $4^{\circ} \mathrm{C}$. At the end of March, the shoots were retrieved and used for cuttings, soaked for $2 \mathrm{~h}$ in Transplantone $(500 \mathrm{mg} / \mathrm{L})$, allowed to develop roots, and cultivated in a greenhouse $\left(25^{\circ} \mathrm{C}\right.$, light 12000 lux $)$. In July, wellgrown and healthy potted plants were selected for further cold stress and total RNA and protein isolation.

\section{Isolation and Sequence Analysis of the VaERD15 Gene}

'Heilongjiang seedling' plants growing in pots were placed in a pre-chilled growth chamber at $4^{\circ} \mathrm{C}$. Young leaves, stems and roots were harvested at $0,2,6,12,24$, and $48 \mathrm{~h}$ after exposure to $4^{\circ} \mathrm{C}$. Samples were frozen in liquid nitrogen prior to extraction of RNA and protein.

Total RNA was extracted using the improved sodium dodecyl sulfate (SDS)/phenol method (Zhang et al., 2003). The firststrand cDNA was synthesized using the Easy Script First-Strand cDNA Synthesis Super Mix (Transgen, China), according to the manufacturer's protocol. The cDNA templates for $5^{\prime}-$ and $3^{\prime}$ Rapid Amplification of cDNA Ends (RACE) were synthesized using the SMARTTM RACE cDNA Amplification Kit (Clontech, Palo Alto, CA, USA). Primers for $5^{\prime}-$ and $3^{\prime}$-RACE are listed in Table 1. All amplified RACE fragments were sequenced three times for each sample. Based on the 5'-RACE and $3^{\prime}$-RACE results, a pair of full-length primers VaERD15-F/R (including initiation and termination codons) were designed (Table 1). Amplification and sequencing of the full-length cDNA of VaERD15 were repeated using two replicates.

The cDNA sequence of VaERD15 gene from $V$. amurensis was translated into amino acid sequences on the NCBI website ${ }^{1}$. The protein conserved domain analysis website ${ }^{2}$ was used to predict conserved domains, theoretical molecular weights and isoelectric

\footnotetext{
${ }^{1}$ http://www.ncbi.nlm.nih.gov/gorf/gorf.html

${ }^{2}$ http://prosite.expasy.org/
} 
TABLE 1 | Primers used in this study.

\begin{tabular}{|c|c|c|c|}
\hline Sr. no. & Primer & Sequence & Amplicon (bp) \\
\hline \multirow[t]{2}{*}{1} & VaERD15-3'RACE & 5'-GTTCGTTCCGTTGGCATATCGGACGGT-3' & \\
\hline & VaERD15-5'RACE & 5'-CTCAAACTACCAGGAAACCCTAACTCGC-3' & \\
\hline \multirow[t]{2}{*}{2} & VaERD15-F(rt VaERD15 -F) & 5'-ATGGCTATGGAGGTAATITCACGTAC -3' & 423 \\
\hline & VaERD15-R(rt VaERD15 -R) & 5' - TTACCGCGGCTGCTGAATCG -3'. & \\
\hline \multirow[t]{2}{*}{3} & VaERD15- Xball-F & 5' -GCTCTAGAATGGCTATGGAGGTAATITCACG-3' & 439 \\
\hline & VaERD15-Kpn I -R & 5'-GGGGTACCCCGCGGCTGCTGAATC-3' & \\
\hline \multirow[t]{2}{*}{4} & VaERD15-Ncol -F(Southern) & 5' -CTAGccatgg ATGGCTATGGAGGTAATTTCACG-3' & 442 \\
\hline & VaERD15-Bglll -R & 5' -GGAagatetCTACGGCGGCTGCTGAATCG-3' & \\
\hline \multirow[t]{2}{*}{5} & Actin 1-F & 5'-GATTCTGGTGATGGTGTGAGT-3' & 168 \\
\hline & Actin1-R & 5'-GACAATTTCCCGTTC AGC AGT-3' & \\
\hline \multirow[t]{2}{*}{6} & AtGAPDH-F & $5^{\prime}-T T G G T G A C$ AAC AGGTC AAGC A-3' & \\
\hline & AtGAPDH-R & 5'-AAACTTGTCGCTCAATGCAATC-3' & \\
\hline \multirow[t]{2}{*}{7} & it AtERD15-F & 5'-AACTTCGACTTGGTACCCTGAT-3' & 116 \\
\hline & it AtERD15 -R & 5'-GAAGATCAGCTACATCGATATGA-3' & \\
\hline
\end{tabular}

points. The homologies of ERD15 in V. amurensis and in corn, pepper and Arabidopsis were analyzed by means of DNAMAN analysis software. Finally, phylogenetic analyses were generated using MEGA 5.0 software ${ }^{3}$.

\section{Expression Pattern Analysis of VaERD15}

Total RNA was extracted from various grapevines after exposure to low-temperature stress $\left(4^{\circ} \mathrm{C}\right)$ for $0,2,6,12,24$, and $48 \mathrm{~h}$, and first-strand CDNA was synthesized, as previously described. Semi-quantitative PCR was carried out using the primers rtVaERD15-F and rtVaERD15-R (Table 1). The volume of the semi-quantitative PCR amplification was $20 \mu \mathrm{l}$, and Actin1 (accession no. AY680701) was used as the internal reference gene. All reactions were repeated for three biological replicates.

Western blotting was carried out to further analyze the expression pattern of $V a E R D 15$. Total protein was extracted from various samples according to the method of Méchin et al. (2006). The extracted protein concentration was determined using the method of Bradford (1976). Proteins samples (25 $\mu \mathrm{g})$ were prepared for SDS-polyacrylamide gel electrophoresis (PAGE), and blotted onto a polyvinylidene fluoride membrane (Roche, product no. 03010040001). Immune antibodies were prepared in our laboratory, as previously reported (Zhang et al., 2014).

\section{Subcellular Localization of VaERD15}

The ORF of VaERD15 without a termination codon was obtained by PCR amplification using specific primers VaERD15-XbalI-F and VaERD15-KpnI-R (Table 1). The PCR products digested by XbalI and KpnI were cloned into a pMD18-T vector (TaKaRa, Japan). The fragments were fused into the $\mathrm{N}$-terminus of the GFP expression vector driven by the $35 \mathrm{~S}$ promoter. The vector carrying 35S::GFP was used as a control. The plasmids of the 35S::VaERD15-GFP fusion construct and 35S::GFP were purified for subsequent experiments. Plasmids were then transformed into onion epidermal cells using the particle bombardment method, as described by Varagona et al. (1992). Transformed

${ }^{3}$ http://www.megasoftware.net onion epidermal cells were cultured on MS media under dark conditions for $24 \mathrm{~h}$ at $25^{\circ} \mathrm{C}$. Expression of the genes transformed into the onion epidermal cells was observed using confocal laser scanning microscopy (LSM 510 META, ZEISS, Germany).

\section{Transcriptional Activation Assay}

For the transcriptional activation assay, the ORF of VaERD15 was generated and fused into the frame to the NcoI and BamHI sites of the GAL4 DNA-binding domain in the pGBKT7 vector by recombination reactions (Invitrogen, USA). The expression vector pGBKT7 carrying the GAL4 gene constructed by our laboratory was used as a positive control and the empty pGBKT7 vector was used as a negative control. These constructs were then transformed into the yeast strain AH109. The resulting transformants were streaked onto Synthetic Defined (SD)/-Trp medium. After incubation at $30^{\circ} \mathrm{C}$ for 3 days, transformed strains on the SD/-Trp plates were selected and streaked onto SD/-Trp/His/-Ade plates containing $\mathrm{x}-\alpha$-gal; the level of transcriptional activation was evaluated by color reaction.

\section{Generation and Detection of Transgenic Arabidopsis Seedlings}

The full-length cDNA of VaERD15 was amplified by PCR and cloned into the BglII/NcoI site of pCAMBIA3301, generating pCAMBIA3301-VaERD15. The specific primers VaERD15-Ncol$\mathrm{F} / \mathrm{R}$ are shown in Table 1. Constructs were verified by sequencing. The constructed plasmid was introduced into Agrobacterium tumefaciens GV3101 cells by electroporation. Transgenic Arabidopsis plants were obtained using the floral dipping method (Clough and Bent, 1998). Putative transgenic Arabidopsis plants harboring the pCAMBIA3301-VaERD15 construct were selected on MS plates containing $10 \mathrm{mg} / \mathrm{L}$ Basta.

Homozygous T3 Arabidopsis strains were tested by PCR and genomic DNA was extracted from 3-week-old leaves of the putative transgenic Arabidopsis seedlings using the cetyltrimethyl ammonium bromide (CTAB) method with appropriate modification (Wu et al., 1998). The specific primers VaERD15-NcoI -F/R were used for amplifying the exogenous 
gene, with pCAMBIA3301-VaERD15 plasmid DNA as a positive control, and DNA from WT Arabidopsis (Col-0) leaves as a negative control. At the same time, leaves of VaERD15-positive Arabidopsis plants were taken for GUS staining, with WT Arabidopsis plants serving as controls.

Southern blot analysis was carried out as previously described Southern (1975). After plant genomic DNA was extracted and purified, $50 \mu \mathrm{g}$ DNA was digested by the restriction enzyme HindIII in $40 \mu \mathrm{l}$ for $12 \mathrm{~h}$. Electrophoresis and Southern blot analysis were then carried out according to the standard methods.

\section{Cold Tolerance, qRT-PCR and Western Blot Assay}

Two T3 Arabidopsis lines (L1, L2) were used for the cold tolerance assay. Similarly, robust transgenic and WT 3-week-old Arabidopsis plants were used for the cold treatment. Plants were placed in a pre-chilled chamber at $4^{\circ} \mathrm{C}$ to cold acclimate for $48 \mathrm{~h}$, and then transferred to a pre-chilled chamber at $-6^{\circ} \mathrm{C}$ for $72 \mathrm{~h}$. Plants suffering from cold stress were transferred to room temperature (approximately $23^{\circ} \mathrm{C}$ ) for 5 days to recover. The phenotypic changes of Arabidopsis plants were observed and photographed during this period. Leaf samples were collected at $0,2,4,8,12,24,48$, and $72 \mathrm{~h}$ after exposure to cold stress and stored at $-80^{\circ} \mathrm{C}$ for qRT-PCR and Western blot analyses. qRT-PCR was carried out to determine expression changes of VaERD15 and AtERD15 [primers: rtVaERD15-F/R and rtAtERD15- F/R (Table 1)], in vivo, using the Takara SYBR Premix Ex Taq ${ }^{\mathrm{TM}}$ II (Perfect Real Time) on a Bio-Rad IQ5 Real-Time PCR Detection System (Bio-Rad Laboratories, Hercules, CA, USA). The volume used for qRT-PCR amplification was $20 \mu \mathrm{l}$, and AtGAPDH (accession no. 101214) was used as the endogenous reference gene. Western blotting was carried out as previously described. All experiments were carried out for three biological replicates.

\section{Biochemical Indicator Assays of Transgenic Arabidopsis}

Biochemical indices relating to cold stress were determined in 3-week-old Arabidopsis seedlings in both transgenic and control plants. All plants had been subjected to the cold treatment described above. Determinations in this part of the study were carried out for three biological replicates.

Relative electrolyte leakage was assessed according to the previously described method (Weigel et al., 2001). Proline content was determined following the method of Shan et al. (2007). MDA content was measured according to the method of Puckette et al. (2007) with minor modifications. About $200 \mathrm{mg}$ leaves frozen in liquid nitrogen was homogenized in $4 \mathrm{ml}$ $10 \%$ trichloracetic acid (TCA), then centrifuged at 10,000 rpm for $10 \mathrm{~min}$. The supernatant $(2 \mathrm{ml})$ was mixed with $2 \mathrm{ml}$ thiobarbituric acid (TBA) and heated at $95^{\circ} \mathrm{C}$ for $30 \mathrm{~min}$, quickly cooled on ice and then centrifuged at $10,000 \mathrm{rpm}$ for $10 \mathrm{~min}$. The soluble sugar and soluble protein contents were measured according to the methods of Bradford (1976) and Machado et al. (2013), respectively.
The activity of SOD was measured using the nitroblue tetrazolium (NBT) method (Giannopolitis and Ries, 1977; Puyang et al., 2015). POD activity was measured using the method of Pagariya et al. (2012). CAT activity was determined as described by Tseng et al. (2007).

\section{Statistical Analysis}

All physiological data was analyzed using the IBM SPSS Statistics 18.0 software. The differences between the transgenic samples and the corresponding wild type samples were calculated by the independent sample $t$-test. Significant differences were represented by ${ }^{*} P<0.05 ;{ }^{* *} P<0.01$.

\section{RESULTS}

\section{Sequence Analysis of VaERD15}

Specific primers were designed according to the acquired ORF of VaERD15, which had a total length of $423 \mathrm{bp}$ with a $5^{\prime}$-untranslated region (UTR) of $66 \mathrm{bp}$, a $3^{\prime}$-UTR of $196 \mathrm{bp}$ and an intron size of $88 \mathrm{bp}$. VaERD15 encoded a predicted polypeptide of 140 amino acids with a molecular weight of $16.2 \mathrm{kD}$ (Zhang et al., 2014), and pI of 4.80. Alignment analysis with the grapevine genome (Jaillon et al., 2007) showed that VaERD15 was initially located on chromosome 13.

Multiple sequence alignment analysis (Figure 1A) showed the VaERD15 shared 36\% homology with the ZmERD15 predicted protein (accession no. ACG25626.1), 35\% homology with the CaERD15 predicted protein (accession no. ABB89735.1) and 33\% homology with the AtERD15 predicted protein (accession no. AAM64638.1). Phylogenetic analyses (Figure 1B) indicated that the relationship of VaERD15 with other ERDs from similar plant species can be divided into two families. The closest relationship with VaERD15 was found in Vitis vinifera and Cucumis sativus.

\section{Expression Pattern Analysis of VaERD15}

Semi-quantitative PCR and Western blotting were carried out to determine the expression patterns of VaERD15. The relative expressions at transcription level are shown in Figure 2A; the transcript was detected in all tissues measured. At $0 \mathrm{~h}$, high VaERD15 expression was found in stems, low expression in leaves and zero expression in roots. After $2 \mathrm{~h}$ of cold stress, the expression of VaERD15 in stems decreased significantly, but recovered slightly after $12 \mathrm{~h}$. The expression of $\mathrm{VaERD} 15$ in leaves and roots showed a rising trend that peaked at $24 \mathrm{~h}$, but then decreased.

The Western blot analysis results are shown in Figure 2B. We observed $16.2 \mathrm{kD}$ bands on the polyvinylidene difluoride, membrane, indicating that the tissue proteins in roots, stems and leaves of $V$. amurensis accession 'Heilongjiang seedling' specifically reacted with VaERD15 antibodies. VaERD15 expression in leaves increased gradually and peaked at $48 \mathrm{~h}$ under the cold stress treatment. VaERD15 expression in stems showed a downward trend up to $12 \mathrm{~h}$, which recovered at $24 \mathrm{~h}$, but subsequently decreased. In the roots, VaERD15 expression levels increased, with a maximum at $6 \mathrm{~h}$ and a second small peak after $24 \mathrm{~h}$. 


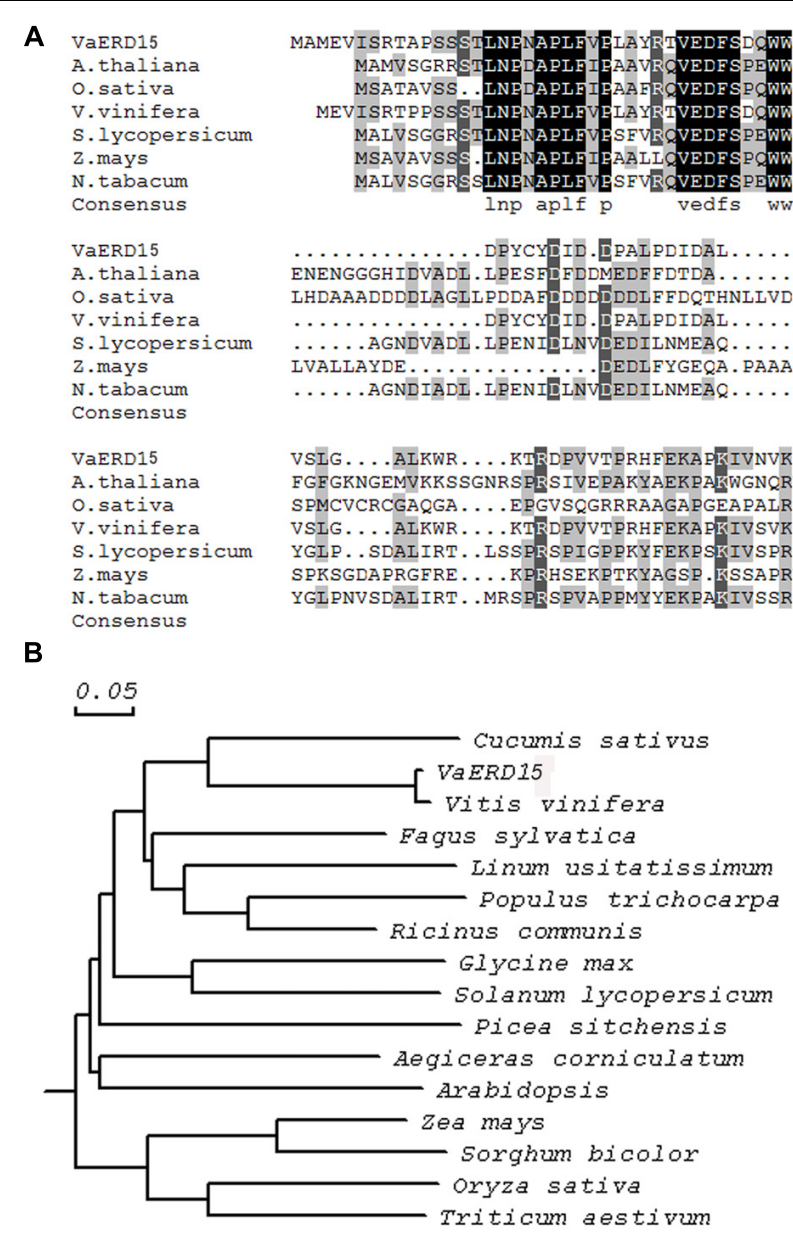

FIGURE 1 | (A) Amino acid sequence alignment of VaERD15 and other ERD15 from similar plant species. (B) Phylogenetic analysis of VaERD15 and other ERD15 from similar plant species. Sequences are from Vitis amurensis (VaERD15, JQ687321), Arabidopsis thaliana (AtERD15, AAM64638.1), Brassica napus (BnERD15, ADP37978.1), Solanum lycopersicum (SIERD15, NP_001234461), Zea mays (ZmERD15, ACG25626.1), and Capsicum annuum (CaERD15, ABB89735.1).

\section{VaERD15 Functions as a Transcription Factor}

The subcellular localization results showed that the $35 \mathrm{~S}$ : VaERD15-GFP fusion expression vector was transiently expressed in onion epidermal cells. Green fluorescence was only observed in the nuclei, while in the control green fluorescence was visible throughout the entire onion cell (Figure 3). This indicates that VaERD15 is localized to the nuclei.

The AH109 strains with the recombinant plasmid of pGBKT7-GAL4 (positive control) and pGBKT7-VaERD15 or the empty pGBKT7 vector (negative control) were all able to grow well on the SD/-Trp medium (Figure 4A). This demonstrates that the pGBKT7-VaERD15 recombinant plasmid, and the positive and negative controls were all transferred into the yeast. The strains transformed with VaERD15 were able to grow well on the $\mathrm{SD} /$-Trp/-His/-Ade $+\mathrm{X}$ - $\alpha$-gal selective medium, and turned blue on the SD/-Trp/-His/-Ade $+\mathrm{X}$ - $\alpha$-gal medium. Accordingly, the negative control did not grow on the SD/-Trp-His-Ade medium (Figure 4B), indicating that VaERD15 could activate the expression of the reporter gene and synthesize the histidine and adenine required for the normal growth of yeast AH109. Taken together, these results illustrate that $V a E R D 15$ could function as a transcriptional activator in yeast.

\section{Molecular Detection of Transgenic Plants}

Arabidopsis plants over-expressing VaERD15 were subjected to PCR. Five T3 Arabidopsis plants that survived on selection medium were used for the PCR experiments, and four expected bands were observed (Figure 5A). We also carried out a GUS staining assay. Results showed that transgenic Arabidopsis leaves were stained blue (Figure 5B), indicating that the GUS was expressed in the plant in vivo. This demonstrates that the plant genome had successfully integrated the target gene VaERD15.

Southern blot analysis was performed using four VaERD15positive lines to further confirm that VaERD15 had been integrated into the Arabidopsis genome. The Southern blot results showed that specific hybridization bands could be clearly observed in all positive lines (Figure 5C), but not in the WT plants. The four transgenic lines all had a specific hybridization signal, but the band sizes were not all the same. This dissimilarity 

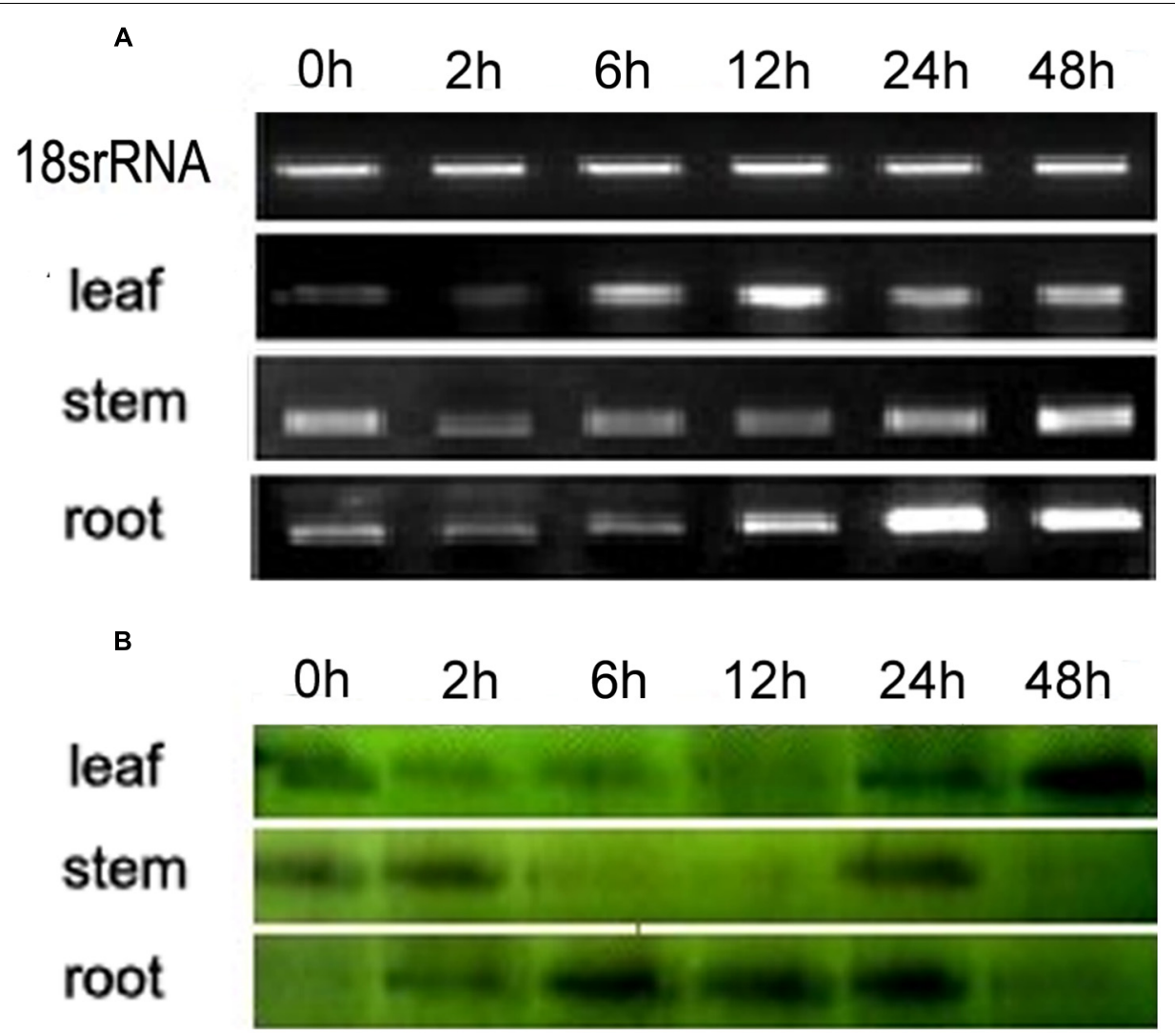

FIGURE 2 | Expression pattern analyses of VaERD15 in different tissues of Vitis amurensis accession 'Heilongjiang seedling' after different periods of cold stress at $4^{\circ} \mathbf{C}$. (A) Semi-quantitative PCR was used to analyze the transcriptional level expression of VaERD15 with Actin1 as a reference gene. (B) Western blotting was carried out to detect the expression levels of VaERD15 protein after cold stress. All experiments were carried out for three biological replicates.

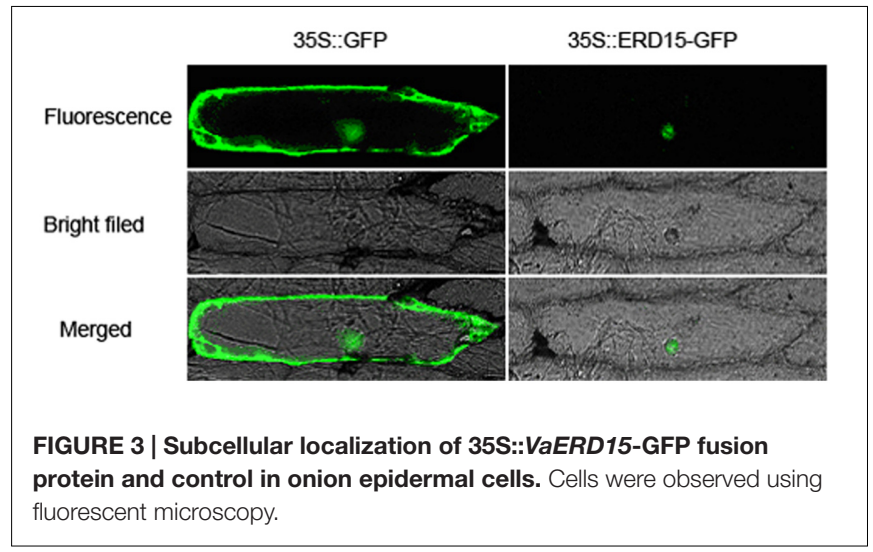

indicates that the transgenic Arabidopsis plants had different insert sites for VaERD15 in their genomes.

\section{Response of VaERD15 to Cold Treatment}

qRT-PCR and Western blotting were carried out to determine expression changes of VaERD15 in vivo. As shown in Figure 6A, VaERD15 transcripts gradually increased in L1 and L2 lines with longer durations of cold stress, but the transcripts were barely detectable in the WT plants. We also detected a change in endogenous AtERD15 after transferring VaERD15 into the Arabidopsis plant. The qRT-PCR results showed that there were no significant differences in the expression of endogenous AtERD15 between wild type and transgenic Arabidopsis, except that the expression in transgenic plants was nearly four times higher than that in WT Arabidopsis at $12 \mathrm{~h}$ (Supplementary Figure S1). Western blot analysis showed that the VaERD15 expression in two transgenic Arabidopsis lines both tended to increase with longer durations of cold stress, and the VaERD15 expression level in L1 was higher than that in L2 (Figure 6B). However, only weak bands were observed in the WT plants, indicating that expression levels of VaERD15 in WT and in transgenic Arabidopsis were different.

\section{VaERD15 Enhanced Cold Tolerance in Arabidopsis}

The cold tolerance assay showed transgenic and WT Arabidopsis were both subjected to freezing injury, but to different extents, with longer durations of cold stress. However, freezing injuries were more serious in WT Arabidopsis. Almost all the transgenic plants suffering from cold stress were able to resume normal growth after being transferred to room-temperature $\left(\sim 23^{\circ} \mathrm{C}\right)$. 


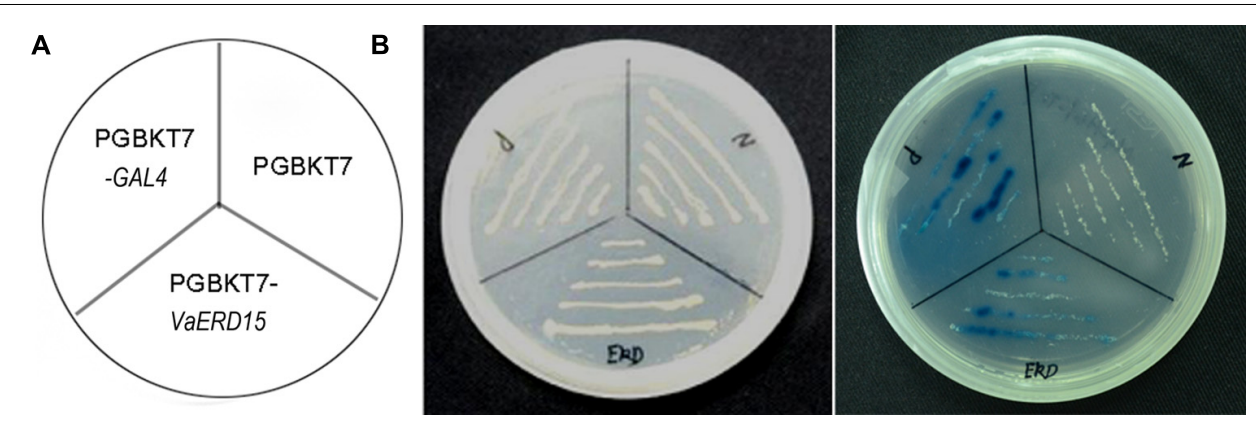

FIGURE 4 | Transcriptional activation assay of VaERD15 in yeast. (A) Fusion proteins of pGBKT7-GAL4 (positive control), pGBKT7-VaERD15 and pGBKT7 vector (negative control) were transformed into the yeast strain AH109. (B)Transformants were streaked onto plates of SD/Trp- and SD/Trp-/His-/Ade- + X- $\alpha-$ gal to detect their growth conditions and $\beta$-galactosidase activity.

However, the same recovery did not occur with the WT plants (Figure 7).

Cold tolerance is strongly correlated with a number of physiological parameters in plants (Liu et al., 2010; Li et al., 2014; $\mathrm{Xu}$ et al., 2014a). To investigate whether the cold tolerance of Arabidopsis lines over-expressing VaERD15 was improved, we measured several cold-related physiological indices including: relative electrolyte leakage; the contents of proline, MDA; soluble sugars and soluble proteins; and the activities of SOD, POD and CAT.

Results showed that relative electrolyte leakage in both transgenic and WT Arabidopsis plants showed an upward trend with longer durations of low temperature treatment (Figure 8A). Both transgenic and WT Arabidopsis plants showed similar conductivities in the early stages of cold stress but after $2 \mathrm{~h}$, the conductivity in the WT plants was significantly higher than that in the transgenic plants. This indicates that WT plants suffered greater cell membrane damage than the transgenic plants.

We also investigated proline and MDA contents (Figures $\mathbf{8 B}, \mathrm{C}$ ). At the start of the stress period, the proline content of the transgenic plants was slightly higher than that of the WT plants but the difference was not significant. After $4 \mathrm{~h}$ of cold stress, proline in the transgenic plants accumulated rapidly, and proline abundance and growth rate were both significantly higher than in the WT plants. Changes in proline content were consistent with the phenotypic changes under cold stress. While the MDA content in the transgenic plants was lower than in the WT plants after $2 \mathrm{~h}$ of cold stress, it increased rapidly with longer durations of cold treatment and was consistently higher than in the WT plants.

Similar to conductivity, the soluble sugar contents of both transgenic and WT Arabidopsis plants increased with longer durations of cold treatment (Figure 8D). The soluble sugar content of the transgenic plants was slightly lower than in the WT plants for the first $12 \mathrm{~h}$ of cold stress, but then accumulated rapidly to become significantly higher than in the WT plants.

As shown in Figure 8E, the soluble protein content of the transgenic plants was consistently higher than that of the WT plants during cold stress. However, the pattern of change was very similar in both plant, falling to a minimum during the first $12 \mathrm{~h}$, and then gradually increasing.
We also measured the activity of antioxidant enzymes. The results showed that SOD activity in transgenic Arabidopsis was consistently higher than in WT plants (Figure 9A), indicating that plants over-expressing VaERD15 generally had elevated SOD activity. POD and CAT activities showed a late increase. The POD content curve of the transgenic plants was relatively flat, but that of the WT plants decreased over the first $8 \mathrm{~h}$ and then increased significantly after $12 \mathrm{~h}$ (Figure 9B). The CAT content in the transgenic plants was lower than in the WT plants at first, but rose slightly after $2 \mathrm{~h}$ (Figure 9C).

\section{DISCUSSION}

Grapes are of considerable economic importance and are grown over large areas of the world. However, close to the cooler limits of where this crop can be grown in the higher latitudes, both north and south of the equator, and at higher altitudes, chilling and frost damage can result in major economic loss. Therefore, the study of genes relating to cold tolerance is crucially important.

ERD genes were first isolated from Arabidopsis suffering from drought stress (Kiyosue et al., 1994). A large number of studies have shown that over-expressing ERD genes can improve the ability of plants to withstand biotic and abiotic stresses. AtERD10 and AtERD14 proteins have been reported to interact with phospholipid vesicles and protect membranes during conditions of high salinity, drought, and low temperature stress (Kovacs et al., 2008). Brassica juncea ERD4 encoding a RNA-binding protein can respond to the induction of dehydration, ABA, salicylic acid, sodium chloride, cold and heat treatments, and overexpressing BjERD4 can improve the tolerance of Arabidopsis plants to salt and dehydration stresses (Rai et al., 2015). Overexpressing Arabidopsis ERD10 can activate CBF/DREB1 genes and enhance the tolerance of plants to cold stress, while a T-DNA insertion mutant of ERD10 is more sensitive than WT plants to cold stress (Kim and Nam, 2010). However, studies involving ERD15 and responses to cold stress are few. In our study, a putative transcription factor $V a E R D 15$, was isolated from a cDNA library of $V$. amurensis induced by low temperatures, and its major function in cold tolerance was investigated. 


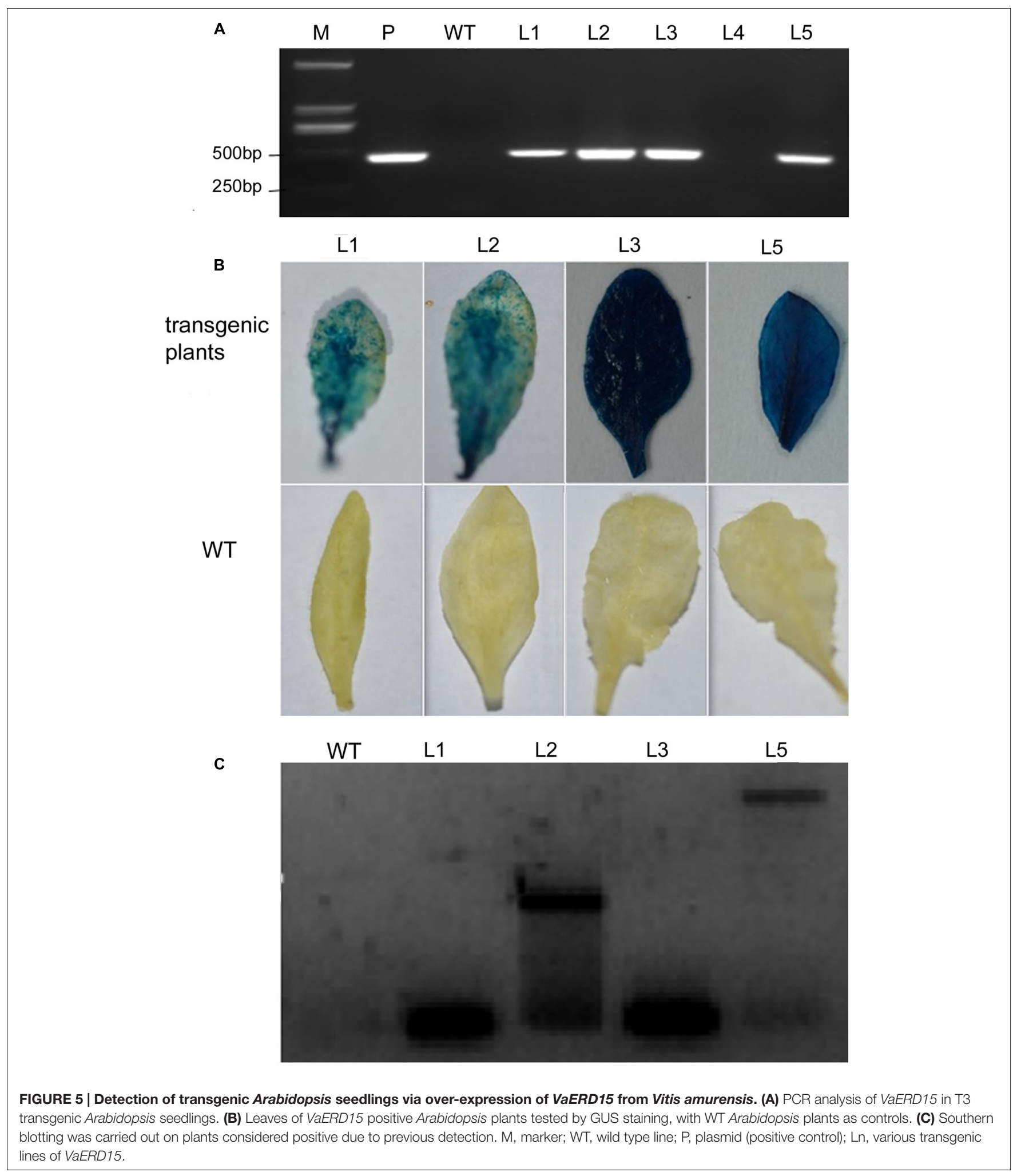

Our results indicate that VaERD15 is expressed in diverse plant tissues, which suggests that VaERD15 is not specific to grapevine. Semi-quantitative PCR results show that accumulation of VaERD15 transcripts in stems is significantly higher than in roots or leaves after $0 \mathrm{~h}$ of chilling. Similar research has shown that transcript accumulation of SpERD15 under non-stress conditions is higher in roots and old leaves of tobacco (Ziaf et al., 2011). Increasing the duration of cold stress led to down-regulation in 
A

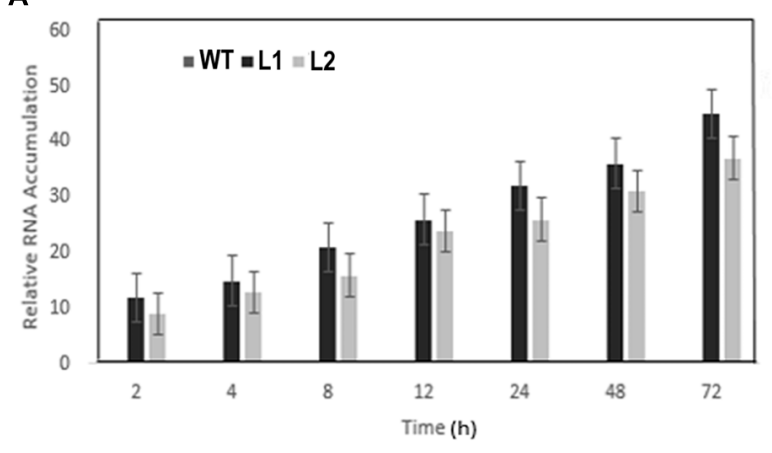

B

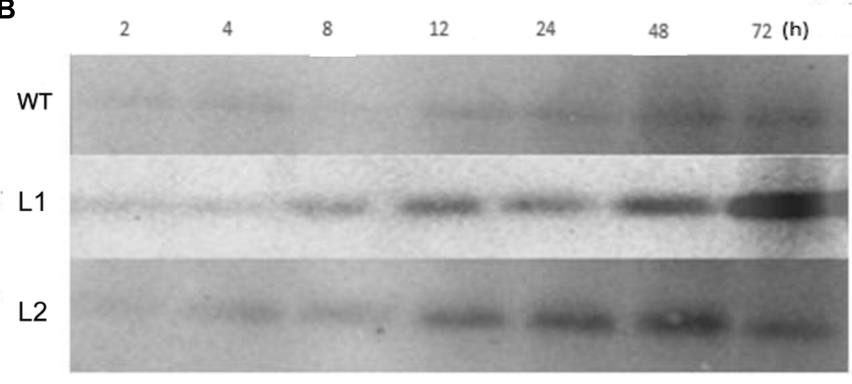

FIGURE 6 | Assessment of ERD15 expression levels in VaERD15-over-expressed Arabidopsis lines at different times of cold stress at -6 ${ }^{\circ}$ C. (A) The relative expression changes of VaERD15 in WT and two transgenic Arabidopsis plants under cold stress. (B) Western blotting was carried out to detect expression changes of target protein in VaERD15-over-expressing Arabidopsis plants induced by cold stress. WT Arabidopsis plants were used as controls. All experiments were carried out for three biological replicates.

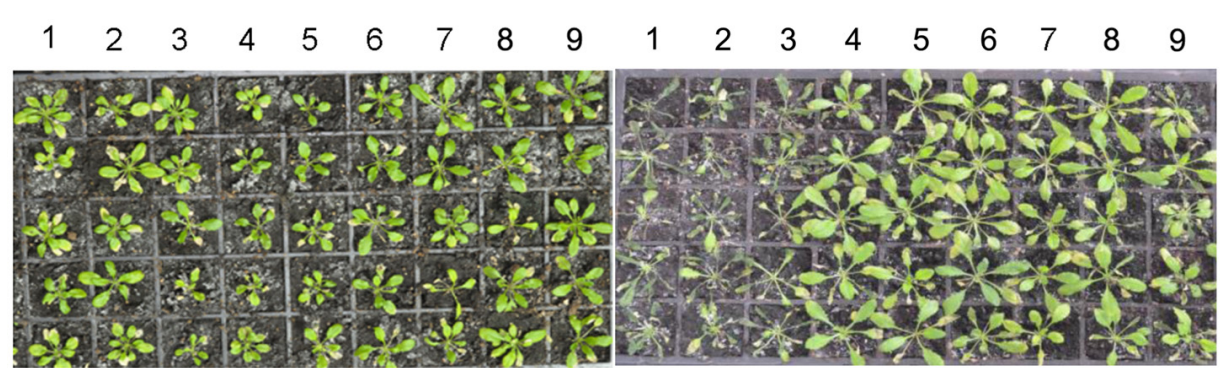

non-stress plants

recovery plants after cold stress

FIGURE 7 | Phenotypic changes of transgenic and WT Arabidopsis lines after 5 days of recovery at room temperature from a cold stress treatment at $-6^{\circ}$ C. 1,2 , and 3 are the WT Arabidopsis lines; 4, 5, and 6 are the transgenic Arabidopsis lines L1; 7, 8, and 9 are the transgenic Arabidopsis lines L2.

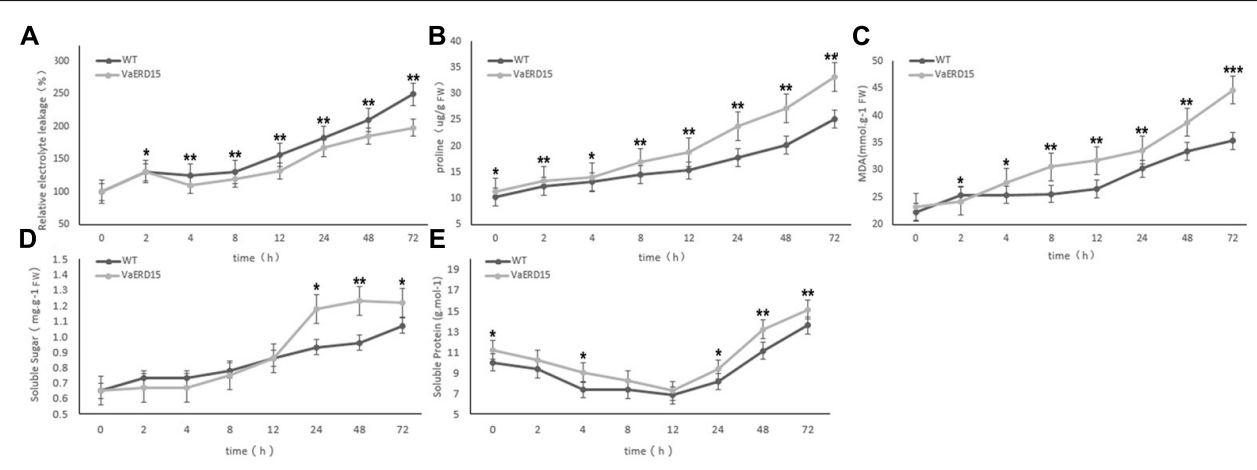

FIGURE 8 | Assessment of cold-tolerance-related physiological indices in transgenic and WT Arabidopsis under cold stress. The changes of transgenic and WT Arabidopsis plants under cold stress in levels of (A) relative electrolyte leakage, (B) proline, (C) MDA, (D) soluble sugar and (E) soluble protein.

Similarly-growing robust transgenic and WT 3-week-old Arabidopsis plants were placed at $-6^{\circ} \mathrm{C}$ for $72 \mathrm{~h}$. Leaf samples were collected at $0,2,4,8,12,24,48$, and $72 \mathrm{~h}$ to assess the relative electrolyte leakage, proline, MDA, soluble sugars and soluble proteins. All determinations were carried out for three biological replicates. Asterisks indicate a significant difference $\left({ }^{*} P<0.05 ;{ }^{*} P<0.01\right)$ compared with the WT Arabidopsis.

the expression of the desired gene in stems, with a concomitant increase in the expression of the gene in leaves and roots. As the expression patterns of VaERD15 in leaves, roots and stems were different, we speculated that after low-temperature treatment of 'Heilongjiang seedling', VaERD15 could be involved in different regulatory pathways. The study by Yan et al. (2006) analyzed mRNA and protein level expression of 44 genes from Oryza sativa, and of the 27 up-regulated genes at the protein level, only five were up-regulated at a transcriptional level due to low-temperature treatment. Baginsky et al. (2005) also found 

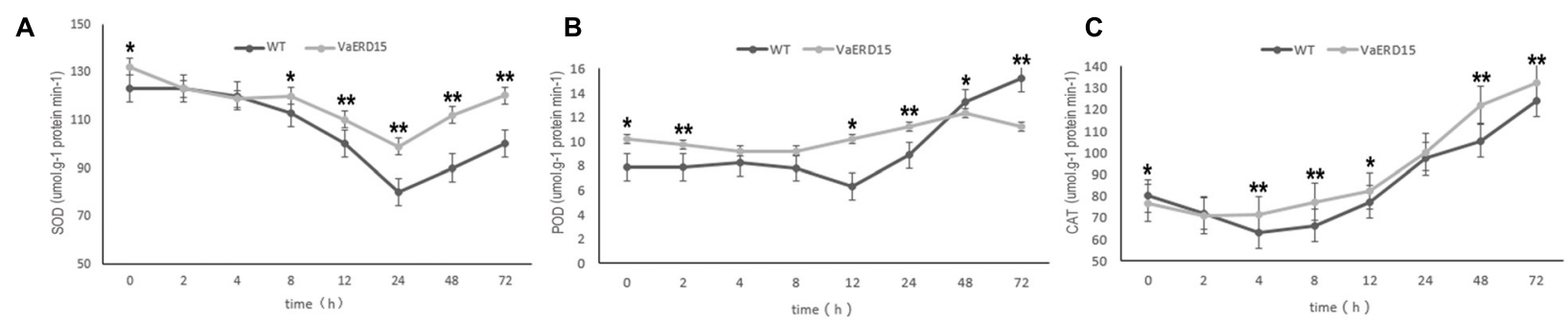

FIGURE 9 | Assessment of the activity of antioxidant enzymes in transgenic and WT Arabidopsis plants under cold stress. Changes in (A) SOD, (B) POD, (C) CAT activities in transgenic and WT Arabidopsis shoots after being subjected to cold stress. Similarly-growing robust transgenic and WT 3-week-old Arabidopsis plants were exposed to $-6^{\circ} \mathrm{C}$ for $72 \mathrm{~h}$. Leaf samples were collected at $0,2,4,8,12,24,48$, and $72 \mathrm{~h}$ to determine the activities of SOD, POD and CAT. All determinations were carried out for three biological replicates. Asterisks indicate a significant difference $\left(^{*} P<0.05\right.$; $\left.{ }^{* *} P<0.01\right)$ compared with the WT Arabidopsis.

that the correlation in expression at the mRNA and protein levels was lower when Arabidopsis chloroplasts and pollen were studied. This phenomenon, i.e., asynchrony in transcription and translation, can be caused by post-translational modifications in the protein-expression process, as well as by operator error (Baldi and Long, 2001). These previous reports support the idea that the expressions of VaERD15 at the mRNA and protein levels are not identical.

Alves et al. (2011b) suggested that GmERD15, as a transcription factor localized to the nucleus and cytoplasm, can activate N-rich protein (NPR) gene expression under osmotic stress. GmERD15 can specifically bind to a 187 bp fragment of $N P R-B$ promoter in yeast, and activate the expression of downstream genes. Ziaf et al. (2011) reported that SpERD15, located mainly in the nucleus, could enhance the plant's ability to resist external stress by increasing the accumulation of intracellular solutes and by inhibiting lipid peroxidation. In this study, the analysis of subcellular localization in onion epidermis showed that VaERD15 was mainly located in the nucleus. Transcription activation experiments confirmed that VaERD15 was able to activate reporter genes in yeast. Therefore, these results show that $\operatorname{VaERD} 15$ acts as a transcription factor.

To verify the function of VaERD15 in mitigating cold stress, Arabidopsis plants over-expressing VaERD15 were generated. A survival assay indicated that Arabidopsis plants over-expressing VaERD15 survived better than WT plants under cold stress. We measured the expression levels of the VaERD15 gene in transgenic Arabidopsis and WT plants and the results showed that the transcripts of VaERD15 increased dramatically with longer durations of cold stress in transgenic Arabidopsis compared with WT plants. This observation is consistent with a number of other studies of cold-related genes in transformed plants (Park et al., 2010; Checker et al., 2012; Kidokoro et al., 2015). In addition, qRT-PCR results showed that the expression levels of endogenous AtERD15 had a slight upward trend in WT plants with increasing duration of cold stress, while the expression of AtERD15 showed a peak at $12 \mathrm{~h}$ in transgenic Arabidopsis, which indicated that the introduction of VaERD15 could enhance the expression of endogenous AtERD15. These results illustrate that these transgenic plants are more tolerant to low temperatures. Further investigation indicated that transgenic
Arabidopsis over-expressing VaERD15 also showed improved cold tolerance.

Physiological assessment showed cell concentrations of proline, MDA, soluble sugars and proteins, were higher in the over-expressing plants than in the WT plants, especially in the later stages of cold stress. These solutes act in different ways to mitigate stress, including protection of cellular structures, scavenging of ROS and detoxification of enzymes (Xiong et al., 2002; Verma and Dubey, 2003). It has been shown that increases in proline expression under drought, cold and salt stresses can help to protect plants from damage (Wanner and Junttila, 1999; Trovato et al., 2008; Xu et al., 2014b). In our study, rapid increases in proline occurred in transgenic plants after $4 \mathrm{~h}$ of cold stress, and after $72 \mathrm{~h}$, proline was 1.5-times higher than in the WT plants. Many studies have reported similar results in plants overexpressing VaICE1 or VaICE2, OsCOIN, OsDREB1 or DREB1, Osmyb4 under cold stress (Ito et al., 2006; Liu et al., 2007; Pasquali et al., 2008; Xu et al., 2014a). Proline accumulation in transgenic plants has been widely reported (Gao et al., 2011; Movahedi et al., 2015; Zhou et al., 2015). Moderate proline accumulations have been observed in transgenic tobacco plants over-expressing SoMYB18 and a tendency for proline to decrease after cold stress has ceased has also been reported. These inconsistent results may be due to the observation that free proline is not a unique physiological index of osmotic potential reduction (Mao et al., 2011).

Electrolyte leakage is a key indicator of membrane injury caused by stress (Dexter et al., 1932; Jaglo-Ottosen et al., 1998). In the early stages, our VaERD15-over-expressing plants and control plants were both able to tolerate cold stress even though their conductivity levels increased. However, under more prolonged stress, the conductivity in the control plants was higher than that in the transgenic plants, indicating greater damage in the controls. The study by Parvanova et al. (2004) was consistent with our results and supported the idea that increased conductivity is indicative of membrane dysfunction.

Malondialdehyde is an end product of lipid peroxidation, and its level is therefore a key indicator of cold stress injury in plants (Jouve et al., 1993; Zhang and Kirkham, 1994). Previous studies on over-expression of OsAPXa, SpERD15 in citrus, rice and tobacco plants reported that, compared with controls, lower 
levels of MDA were found in transgenic plants after exposure to cold stress (Hara et al., 2003; Sato et al., 2011; Ziaf et al., 2011). In contrast with the above, our results showed that after $2 \mathrm{~h}$ of being subjected to cold temperatures, the MDA content of transgenic plants was consistently higher than that of WT plants. However, a similar finding to ours was reported for transgenic tobacco by Parvanova et al. (2004); their results suggested plants develop stress tolerance by producing large amounts of MDA.

Reactive oxygen species accumulation can lead to membrane peroxidation and thus destroy cell structure and function (Mittler et al., 2004). One way in which plants respond to stress is to accelerate free radical scavenging by increasing the activity of protective enzymes. The activities of three antioxidant-related enzymes were measured in our assay. In general, POD activity increased slowly, CAT activity increased rapidly while SOD activity initially increased, then decreased. The time courses of the activity trends for SOD and CAT in our transgenic plants were generally similar to those in WT plants, but the enzyme activities were significantly higher in the transgenic plants. Many reports on environmental stress have recorded the activities of antioxidant enzymes. For example, Yang et al. (2012) confirmed that the activities of POD, SOD and CAT increased in plants over-expressing OsMYB2, under salt stress. However, Yuan et al. (2015) reported that under cold stress, antioxidase activity was not significantly different in VaPAT1-over-expressing plants compared to WT plants. Shingote et al. (2015) found POD and CAT activities fell, while SOD activity increased in transgenic plants under cold stress. This indicates there may be synergy between the various antioxidant enzymes in the presence of active oxygen scavenging. Therefore, we hypothesize that within $24 \mathrm{~h}$ of the imposition of cold stress, the continuing decline in SOD activity that we observed was the result of over-accumulation of CAT in the cell.

We found that in $V$. amurensis the transcription factor VaERD15 can significantly improve the tolerance of plants to low temperatures. Previous reports have shown that over-expression of individual genes can improve tolerance to cold stress (Saijo et al., 2000; Mukhopadhyay et al., 2004; Mishra et al., 2013). Other studies have also indicated that transformation of cold-resistant

\section{REFERENCES}

Aalto, M. K., Helenius, E., Kariola, T., Pennanen, V., Heino, P., Hõrak, H., et al. (2012). ERD15-an attenuator of plant ABA responses and stomatal aperture. Plant Sci. 182, 19-28. doi: 10.1016/j.plantsci.2011.08.009

Alves, M. S., Fontes, E. P., and Fietto, L. G. (2011a). Early responsive to dehydration 15 , a new transcription factor that integrates stress signaling pathways. Plant Signal. Behav. 6, 1993-1996. doi: 10.4161/psb.6.12.18268

Alves, M. S., Reis, P. A., Dadalto, S. P., Faria, J. A., Fontes, E. P., and Fietto, L. G. (2011b). A novel transcription factor, ERD15 (Early Responsive to Dehydration 15), connects endoplasmic reticulum stress with an osmotic stress-induced cell death signal. J. Biol. Chem. 286, 20020-20030. doi: 10.1074/jbc.M111. 233494

Baginsky, S., Kleffmann, T., Von Zychlinski, A., and Gruissem, W. (2005). Analysis of shotgun proteomics and RNA profiling data from Arabidopsis thaliana chloroplasts. J. Proteome Res. 4, 637-640. doi: 10.1021/pr049764u

Baldi, P., and Long, A. D. (2001). A Bayesian framework for the analysis of microarray expression data: regularized t-test and statistical inferences of gene changes. Bioinformatics 17, 509-519. doi: 10.1093/bioinformatics/17.6.509 genes can activate and enhance the expression of related genes under cold stress (Ziaf et al., 2011; Xu et al., 2014a). Therefore, clarifying the interaction between $V a E R D 15$ and other genes appears to be a promising direction for future research in this field. In summary, our findings confirm the significant value of continued investigation into the function and mechanisms of $E R D$ genes in grapes, for the further development of cold-tolerant strains.

\section{AUTHOR CONTRIBUTIONS}

DY: Expression and analysis of VaERD15 in Arabidopsis, determining the physiological and biochemical indices for transgenic plants. LZ: RT-PCR analysis of AtERD15, data collation and manuscript writing. KZ: Subcellular localization of VaERD15 and transcriptional activation analysis of VaERD15. $\mathrm{RN}$ : Cloning and sequence analysis of VaERD15 gene, as well as RT-PCR analysis for V. amurensis. HZ: Semi-quantitative RTPCR analysis for $V$. amurensis. JZ: Experimental design, plant material preparation and manuscript modification.

\section{ACKNOWLEDGMENTS}

This work received financial support from The National ScienceTechnology Support Plan Projects from the Ministry of Science and Technology of the People's Republic of China (grant no. 2013BAD02B04-06).

\section{SUPPLEMENTARY MATERIAL}

The Supplementary Material for this article can be found online at: http://journal.frontiersin.org/article/10.3389/fpls.2017.00297/ full\#supplementary-material

FIGURE S1 | The relative expression changes of VaERD15 and AtERD15 in transgenic and WT Arabidopsis plants under cold stress. All experiments were carried out for three biological replicates.

Bradford, M. M. (1976). A rapid and sensitive method for the quantitation of microgram quantities of protein utilizing the principle of proteindye binding. Anal. Biochem. 72, 248-254. doi: 10.1016/0003-2697(76) 90527-3

Checker, V. G., Chhibbar, A. K., and Khurana, P. (2012). Stress-inducible expression of barley Hval gene in transgenic mulberry displays enhanced tolerance against drought, salinity and cold stress. Transgenic Res. 21, 939-957. doi: 10.1007/s11248-011-9577-8

Clough, S. J., and Bent, A. F. (1998). Floral dip: a simplified method for Agrobacterium-mediated transformation of Arabidopsis thaliana. Plant J. 16, 735-743. doi: 10.1046/j.1365-313x.1998.00343.x

Dexter, S. T., Tottingham, W., and Graber, L. (1932). Investigations of the hardiness of plants by measurement of electrical conductivity. Plant Physiol. 7, 63-78.

Gao, J.-J., Zhang, Z., Peng, R.-H., Xiong, A.-S., Xu, J., Zhu, B., et al. (2011). Forced expression of Mdmyb10, a myb transcription factor gene from apple, enhances tolerance to osmotic stress in transgenic Arabidopsis. Mol. Biol. Rep. 38, 205-211. doi: 10.1007/s11033-010-0096-0

Giannopolitis, C. N., and Ries, S. K. (1977). Superoxide dismutases I. Occurrence in higher plants. Plant Physiol. 59, 309-314. doi: 10.1104/pp.59.2.309 
Hara, M., Terashima, S., Fukaya, T., and Kuboi, T. (2003). Enhancement of cold tolerance and inhibition of lipid peroxidation by citrus dehydrin in transgenic tobacco. Planta 217, 290-298. doi: 10.1007/s00425-003-0986-7

He, P.-C., and Niu, L.-X. (1989). Studies on cold resistance of wild Vitis species. Acta Hortic. Sin. 16, 81-88.

Ito, Y., Katsura, K., Maruyama, K., Taji, T., Kobayashi, M., Seki, M., et al. (2006). Functional analysis of rice DREB1/CBF-type transcription factors involved in cold-responsive gene expression in transgenic rice. Plant Cell Physiol. 47, 141-153. doi: 10.1093/pcp/pci230

Jaglo-Ottosen, K. R., Gilmour, S. J., Zarka, D. G., Schabenberger, O., and Thomashow, M. F. (1998). Arabidopsis CBF1 overexpression induces COR genes and enhances freezing tolerance. Science 280, 104-106. doi: 10.1126/ science.280.5360.104

Jaillon, O., Aury, J.-M., Noel, B., Policriti, A., Clepet, C., Casagrande, A., et al. (2007). The grapevine genome sequence suggests ancestral hexaploidization in major angiosperm phyla. Nature 449, 463-467. doi: 10.1038/nature 06148

Jeandet, P., Bessis, R., Maume, B. F., Meunier, P., Peyron, D., and Trollat, P. (1995). Effect of enological practices on the resveratrol isomer content of wine. J. Agric. Food Chem. 2, 316-319. doi: 10.1021/jf00050a010

Jouve, L., Engelmann, F., Noirot, M., and Charrier, A. (1993). Evaluation of biochemical markers (sugar, proline, malonedialdehyde and ethylene) for cold sensitivity in microcuttings of two coffee species. Plant Sci. 91, 109-116. doi: 10.1016/0168-9452(93)90194-5

Kariola, T., Brader, G., Helenius, E., Li, J., Heino, P., and Palva, E. T. (2006). Early responsive to dehydration 15 , a negative regulator of abscisic acid responses in Arabidopsis. Plant Physiol. 142, 1559-1573. doi: 10.1104/pp.106.086223

Kidokoro, S., Watanabe, K., Ohori, T., Moriwaki, T., Maruyama, K., Mizoi, J., et al. (2015). Soybean DREB1/CBF-type transcription factors function in heat and drought as well as cold stress-responsive gene expression. Plant J. 81, 505-518. doi: $10.1111 /$ tpj. 12746

Kim, S. Y., and Nam, K. H. (2010). Physiological roles of ERD10 in abiotic stresses and seed germination of Arabidopsis. Plant Cell Rep. 29, 203-209. doi: 10.1007/ s00299-009-0813-0

Kiyosue, T., Abe, H., Yamaguchi-Shinozaki, K., and Shinozaki, K. (1998). ERD6, a cDNA clone for an early dehydration-induced gene of Arabidopsis, encodes a putative sugar transporter. Biochim. Biophys. Acta 1370, 187-191. doi: 10.1016/ S0005-2736(98)00007-8

Kiyosue, T., Yamaguchi-Shinozaki, K., and Shinozaki, K. (1994). Cloning of cDNAs for genes that are early-responsive to dehydration stress (ERDs) in Arabidopsis thaliana L.: identification of three ERDs as HSP cognate genes. Plant Mol. Biol. 25, 791-798. doi: 10.1007/BF00028874

Kovacs, D., Kalmar, E., Torok, Z., and Tompa, P. (2008). Chaperone activity of ERD10 and ERD14, two disordered stress-related proteins. Plant Physiol. 147, 381-390. doi: 10.1104/pp.108.118208

Li, J., Wang, L., Zhu, W., Wang, N., Xin, H., and Li, S. (2014). Characterization of two VvICE1 genes isolated from 'Muscat Hamburg' grapevine and their effect on the tolerance to abiotic stresses. Sci. Hortic. 165, 266-273. doi: 10.1016/j. scienta.2013.11.002

Liu, K., Wang, L., Xu, Y., Chen, N., Ma, Q., Li, F., et al. (2007). Overexpression of OsCOIN, a putative cold inducible zinc finger protein, increased tolerance to chilling, salt and drought, and enhanced proline level in rice. Planta 226, 1007-1016. doi: 10.1007/s00425-007-0548-5

Liu, L., Duan, L., Zhang, J., Zhang, Z., Mi, G., and Ren, H. (2010). Cucumber (Cucumis sativus L.) over-expressing cold-induced transcriptome regulator ICE1 exhibits changed morphological characters and enhances chilling tolerance. Sci. Hortic. 124, 29-33. doi: 10.1016/j.scienta.2009. 11.018

Liu, Y., Li, H., Shi, Y., Song, Y., Wang, T., and Li, Y. (2009). A maize early responsive to dehydration gene, $\mathrm{ZmERD} 4$, provides enhanced drought and salt tolerance in Arabidopsis. Plant Mol. Biol. Rep. 27, 542-548. doi: 10.1007/s11105009-0119-y

Machado, R. A., Ferrieri, A. P., Robert, C. A., Glauser, G., Kallenbach, M., Baldwin, I. T., et al. (2013). Leaf-heribivore attack reduces carbon reserves and regrowth from the roots via jasmonate and auxin signaling. New Phytol. 200, 1234-1236. doi: 10.1111/nph.12438

Mao, X., Jia, D., Li, A., Zhang, H., Tian, S., Zhang, X., et al. (2011). Transgenic expression of TaMYB2A confers enhanced tolerance to multiple abiotic stresses in Arabidopsis. Funct. Integr. Genomics 11, 445-465. doi: 10.1007/s10142-0110218-3

Méchin, V., Damerval, C., and Zivy, M. (2006). Total protein extraction with TCA-acetone. Methods Mol. Biol. 355, 1-8. doi: 10.1385/1-59745-227-0:1

Mishra, M. K., Chaturvedi, P., Singh, R., Singh, G., Sharma, L. K., Pandey, V., et al. (2013). Overexpression of WsSGTL1 gene of Withania somnifera enhances salt tolerance, heat tolerance and cold acclimation ability in transgenic Arabidopsis plants. PLoS ONE 8:e63064. doi: 10.1371/journal.pone.0063064

Mittler, R., Vanderauwera, S., Gollery, M., and Van Breusegem, F. (2004). Reactive oxygen gene network of plants. Trends Plant Sci. 9, 490-498. doi: 10.1016/j. tplants.2004.08.009

Movahedi, A., Zhang, J., Yin, T., and Zhuge, Q. (2015). Functional analysis of two orthologous NAC Genes, CarNAC3, and CarNAC6 from Cicer arietinum, involved in abiotic stresses in poplar. Plant Mol. Biol. Rep. 33, 1539-1551. doi: 10.1007/s11105-015-0855-0

Mukhopadhyay, A., Vij, S., and Tyagi, A. K. (2004). Overexpression of a zincfinger protein gene from rice confers tolerance to cold, dehydration, and salt stress in transgenic tobacco. Proc. Natl. Acad. Sci. U.S.A. 101, 6309-6314. doi: 10.1073/pnas.0401572101

Pagariya, M. C., Devarumath, R. M., and Kawar, P. G. (2012). Biochemical characterization and identification of differentially expressed candidate genes in salt stressed sugarcane. Plant Sci. 184, 1-13. doi: 10.1016/j.plantsci.2011.12.002

Park, M. R., Yun, K. Y., Mohanty, B., Herath, V., Xu, F., Wijaya, E., et al. (2010). Supra-optimal expression of the cold-regulated OsMyb4 transcription factor in transgenic rice changes the complexity of transcriptional network with major effects on stress tolerance and panicle development. Plant Cell Environ. 33, 2209-2230. doi: 10.1111/j.1365-3040.2010.02221.x

Parvanova, D., Ivanov, S., Konstantinova, T., Karanov, E., Atanassov, A., Tsvetkov, T., et al. (2004). Transgenic tobacco plants accumulating osmolytes show reduced oxidative damage under freezing stress. Plant Physiol. Biochem. 42, 57-63. doi: 10.1016/j.plaphy.2003.10.007

Pasquali, G., Biricolti, S., Locatelli, F., Baldoni, E., and Mattana, M. (2008). Osmyb4 expression improves adaptive responses to drought and cold stress in transgenic apples. Plant Cell Rep. 27, 1677-1686. doi: 10.1007/s00299-008-0587-9

Puckette, M. C., Weng, H., and Mahalingam, R. (2007). Physiological and biochemical responses to acute ozone-induced oxidative stress in Medicago truncatula. Plant Physiol. Biochem. 45, 70-79. doi: 10.1016/j.plaphy.2006. 12.004

Puyang, X., An, M., Han, L., and Zhang, X. (2015). Protective effect of spermidine on salt stress induced oxidative damage in two Kentucky bluegrass ( $P$ oa pratensis L.) cultivars. Ecotoxicol. Environ. Saf. 117, 96-106. doi: 10.1016/j. ecoenv.2015.03.023

Rai, A., Suprasanna, P., D’souza, S. F., and Kumar, V. (2012). Membrane topology and predicted RNA-binding function of the 'early responsive to dehydration (ERD4)' plant protein. PLoS ONE 7:e32658. doi: 10.1371/journal.pone.0032658

Rai, A. N., Tamirisa, S., Rao, K., Kumar, V., and Suprasanna, P. (2015). Brassica RNA binding protein ERD4 is involved in conferring salt, drought tolerance and enhancing plant growth in Arabidopsis. Plant Mol. Biol. 90, 375-387. doi: 10.1007/s11103-015-0423-x

Saijo, Y., Hata, S., Kyozuka, J., Shimamoto, K., and Izui, K. (2000). Over-expression of a single $\mathrm{Ca}^{2+}$-dependent protein kinase confers both cold and salt/drought tolerance on rice plants. Plant J. 23, 319-327. doi: 10.1046/j.1365-313x.2000. 00787.x

Sato, Y., Masuta, Y., Saito, K., Murayama, S., and Ozawa, K. (2011). Enhanced chilling tolerance at the booting stage in rice by transgenic overexpression of the ascorbate peroxidase gene, OsAPXa. Plant Cell Rep. 30, 399-406. doi: 10.1007/s00299-010-0985-7

Shan, D. P., Huang, J. G., Yang, Y. T., Guo, Y. H., Wu, C. A., Yang, G. D., et al. (2007). Cotton GhDREB1 increases plant tolerance to low temperature and is negatively regatively regulated by gibberellic acid. New Phytol. 176, 70-81. doi: 10.1111/j.1469-8137.2007.02160.x

Shao, H., Chen, S., Zhang, K., Cao, Q., Zhou, H., Ma, Q., et al. (2014). Isolation and expression studies of the ERD15 gene involved in drought-stressed responses. Genet. Mol. Res. 13, 10852-10862. doi: 10.4238/2014.December.19.6

Shingote, P. R., Kawar, P. G., Pagariya, M. C., Kuhikar, R. S., Thorat, A. S., and Babu, K. (2015). SoMYB18, a sugarcane MYB transcription factor improves salt and dehydration tolerance in tobacco. Acta Physiol. Plant. 37, 1-12. doi: 10.1007/s11738-015-1961-1 
Southern, E. M. (1975). Detection of specific sequences among DNA fragments separated by gel electrophoresis. J. Mol. Biol. 98, 503-517. doi: 10.1016/S00222836(75)80083-0

Trovato, M., Mattioli, R., and Costantino, P. (2008). Multiple roles of proline in plant stress tolerance and development. Rend. Lincei 19, 325-346. doi: 10.1007/ s12210-008-0022-8

Tseng, M. J., Liu, C.-W., and Yiu, J.-C. (2007). Enhanced tolerance to sulfur dioxide and salt stress of transgenic Chinese cabbage plants expressing both superoxide dismutase and catalase in chloroplasts. Plant Physiol. Biochem. 45, 822-833. doi: 10.1016/j.plaphy.2007.07.011

Varagona, M. J., Schmidt, R. J., and Raikhel, N. V. (1992). Nuclear localization signal (s) required for nuclear targeting of the maize regulatory protein Opaque2. Plant Cell 4, 1213-1227. doi: 10.1105/tpc.4.10.1213

Verma, S., and Dubey, R. (2003). Lead toxicity induces lipid peroxidation and alters the activities of antioxidant enzymes in growing rice plants. Plant Sci. 164, 645-655. doi: 10.1016/S0168-9452(03)00022-0

Wanner, L. A., and Junttila, O. (1999). Cold-induced freezing tolerance in Arabidopsis. Plant Physiol. 120, 391-400. doi: 10.1104/pp.120.2.391

Weigel, R. R., Bäuscher, C., Pfitzner, A. J., and Pfitzner, U. M. (2001). NIMIN-1, NIMIN-2 and NIMIN-3, members of a novel family of proteins from Arabidopsis that interact with NPR1/NIM1, a key regulator of systemic acquired resistance in plants. Plant Mol. Biol. 46, 143-160. doi: 10.1023/A: 1010652620115

Wu, D., Lin, Q., and Li, G. (1998). Cetyltrimethyl ammonium bromide (CTAB) method for extracting Rhizophora apiculata's DNA and its random amplified polymorphic DNA (RAPD) reaction. Chin. J. Biochem. Mol. Biol. 15, 67-70.

Xiong, L., Schumaker, K. S., and Zhu, J.-K. (2002). Cell signaling during cold, drought, and salt stress. Plant Cell 14, S165-S183. doi: 10.1105/tpc. 000596

Xu, W., Jiao, Y., Li, R., Zhang, N., Xiao, D., Ding, X., et al. (2014a). Chinese wildgrowing Vitis amurensis ICE1 and ICE2 encode MYC-type bHLH transcription activators that regulate cold tolerance in Arabidopsis. PLoS ONE 9:e102303. doi: 10.1371/journal.pone.0102303

Xu, W., Li, R., Zhang, N., Ma, F., Jiao, Y., and Wang, Z. (2014b). Transcriptome profiling of Vitis amurensis, an extremely cold-tolerant Chinese wild Vitis species, reveals candidate genes and events that potentially connected to cold stress. Plant Mol. Biol. 86, 527-541. doi: 10.1007/s11103-014-0245-2

Yan, S.-P., Zhang, Q.-Y., Tang, Z.-C., Su, W.-A., and Sun, W.-N. (2006). Comparative proteomic analysis provides new insights into chilling stress responses in rice. Mol. Cell. Proteom. 5, 484-496. doi: 10.1074/mcp.M500251MCP200

Yang, A., Dai, X., and Zhang, W.-H. (2012). A R2R3-type MYB gene, OsMYB2, is involved in salt, cold, and dehydration tolerance in rice. J. Exp. Bot. 63, 2541-2556. doi: 10.1093/jxb/err431
Yang, J., Timothy, E. M., and Liu, R. H. (2009). Phytochemical profiles and antioxidant activities of wine grapes. Food Chem. 116, 332-339. doi: 10.1016/ j.foodchem.2009.02.021

Yuan, Y., Fang, L., Karungo, S. K., Zhang, L., Gao, Y., Li, S., et al. (2015). Overexpression of VaPAT1, a GRAS transcription factor from Vitis amurensis, confers abiotic stress tolerance in Arabidopsis. Plant Cell Rep. 35, 655-666. doi: 10.1007/s00299-015-1910-x

Zhang, J., and Kirkham, M. (1994). Drought-stress-induced changes in activities of superoxide dismutase, catalase, and peroxidase in wheat species. Plant Cell Physiol. 35, 785-791. doi: 10.1093/oxfordjournals.pcp.a078658

Zhang, J.-J., Wang, Y.-J., Wang, X.-P., Yang, K.-Q., and Yang, J.-X. (2003). An improved method for rapidly extracting total RNA from Vitis. J. Fruit Sci. 3:126.

Zhang, J., Wu, X., Niu, R., Liu, Y., Liu, N., Xu, W., et al. (2012). Cold-resistance evaluation in 25 wild grape species. Vitis 51, 153-160.

Zhang, J., Liu, N., Niu, R., Liu, Y., Zhai, H., Xu, W., et al. (2013). Construction of a cDNA library of the Chinese wild Vitis amurensis under cold stress and analysis of potential hardiness-related expressed sequence tags. Genet. Mol. Res. 12, 1182-1193. doi: 10.4238/2013.April.12.5

Zhang, J.-X., Zhai, H., Niu, R.-X., and Li, R.-M. (2014). Prokaryotic expression and polyclonal antibody preparation of China wild Vitis amurensis. J. Northwest For. Univ. 29, 100-105.

Zhou, M., Wang, C., Qi, L., Yang, X., Sun, Z., Tang, Y., et al. (2015). Ectopic expression of Fagopyrum tataricum FtMYB12 improves cold tolerance in Arabidopsis thaliana. J. Plant Growth Regul. 34, 362-371. doi: 10.1007/s00344014-9472-7

Ziaf, K., Loukehaich, R., Gong, P., Liu, H., Han, Q., Wang, T., et al. (2011). A multiple stress-responsive gene ERD15 from Solanum pennellii confers stress tolerance in tobacco. Plant Cell Physiol. 52, 1055-1067. doi: 10.1093/pcp/ pcr057

Ziaf, K., Munis, M. F. H., Samin, G., Zhang, X., Li, J., Zhang, J., et al. (2016). Characterization of ERD15 gene from cultivated tomato (Solanum lycopersicum). Pak. J. Agric. Sci. 53, 27-33. doi: 10.21162/PAKJAS/16. 3695

Conflict of Interest Statement: The authors declare that the research was conducted in the absence of any commercial or financial relationships that could be construed as a potential conflict of interest.

Copyright (c) 2017 Yu, Zhang, Zhao, Niu, Zhai and Zhang. This is an open-access article distributed under the terms of the Creative Commons Attribution License (CC BY). The use, distribution or reproduction in other forums is permitted, provided the original author(s) or licensor are credited and that the original publication in this journal is cited, in accordance with accepted academic practice. No use, distribution or reproduction is permitted which does not comply with these terms. 